\title{
Hypnotic suggestions of safety improve well-being in non-invasively ventilated patients in the intensive care unit
}

\author{
Barbara Schmidt ${ }^{*}\left(\mathbb{D}\right.$, Jana Schneider ${ }^{1}$, Teresa Deffner ${ }^{2}$ and Jenny Rosendahl ${ }^{3}$
}

(c) 2021 The Author(s)

\section{Dear Editor,}

Patients in the intensive care unit (ICU) are facing a threatening environment while their health is at risk [1]. In addition, the non-invasive ventilation procedure causes stress and anxiety which reduce cooperation [2]. We developed an intervention containing hypnotic suggestions to improve patients' well-being during non-invasive ventilation in the ICU [3-5]. The aim of this study was to test the feasibility, safety, and acceptance of this intervention. Our main hypothesis was that subjective ratings will be improved after the intervention.

We used a pre-post-design with subjective ratings of patients before and after the intervention. During the intervention, patients received non-invasive ventilation and their physiological responses were measured by standard vital sign recordings. The protocol of this study was published previously [4]. Our study was approved by the ethics committee of the Jena University Hospital in Germany (\#2019-1463; July 15, 2019).

We included patients who were afraid of non-invasive ventilation due to previous experience. Exclusion criteria were a Glasgow Coma Scale value below 14, delirium, lack of orientation, being deaf or not fluent in German language. All patients signed an informed consent statement.

Two female psychology master students trained by B. S. performed the intervention. Before and after the non-invasive ventilation session, patients rated their subjective valence, arousal and anxiety as well as their

\footnotetext{
*Correspondence: schmidt.barbara@uni-jena.de

${ }^{1}$ Friedrich Schiller University, Institute of Psychology, Jena, Germany

Full author information is available at the end of the article

Teresa Deffner and Jenny Rosendahl contributed equally.
}

subjective breathing mask comfort. To start non-invasive ventilation, a member of the clinical staff put the breathing mask on the patients' face. The trained psychologist sat down next to the patient and explained the following procedure. The intervention was applied via a standardized verbatim text available as supplementary material. The approximate duration of each experimental event is reported in the supplementary material. In total, the intervention lasted about 15 min Fig. 1a.

We obtained data of 31 patients (mean age 63.9 years [SD 11], 14 female and 17 male). Patients rated their subjective valence as significantly more positive, $d=0.69$ (95\% CI 0.3-1.09), their subjective arousal as significantly lower, $d=0.67$ (95\% CI $0.28-1.07)$ and their anxiety as significantly lower, $d=0.85$ (95\% CI $0.44-1.28)$ after the intervention compared to before the intervention. Patients rated the breathing mask as significantly more comfortable after the intervention compared to before the intervention, $d=1.08$ (95\% CI 0.62-1.57) Fig. $1 \mathrm{~b}$. Physiological responses show that breathing rate and heart rate decreased during the intervention, shown by significant main effects of the event for breathing rate, $F(8,224)=7.4, p<0.001, \eta^{2}{ }_{\mathrm{G}}=0.21(95 \%$ CI $0.1-0.28)$ and heart rate, $F(8,224)=5.7, p<0.001, \eta^{2}{ }_{\mathrm{G}}=0.17(95 \% \mathrm{CI}$ $0.07-0.24)$. Detailed results are available as supplementary material.

This study shows the feasibility, safety, and acceptance of hypnotic suggestions to increase well-being during non-invasive ventilation in the ICU. Future randomized-controlled studies should test the efficacy of the intervention against suitable control groups including a group receiving non-invasive ventilation without hypnotic suggestions. We conclude that hypnotic suggestions can improve well-being during challenging

\section{实




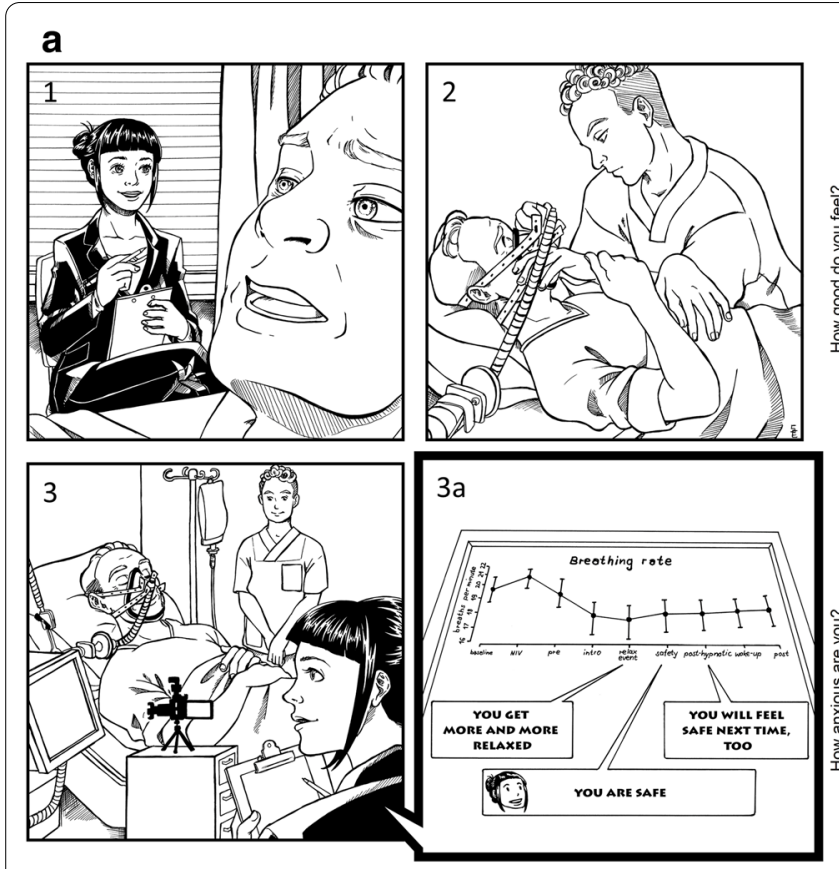



Anxiety rating

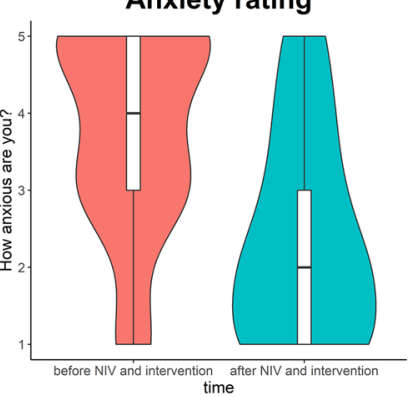



NIV-mask rating

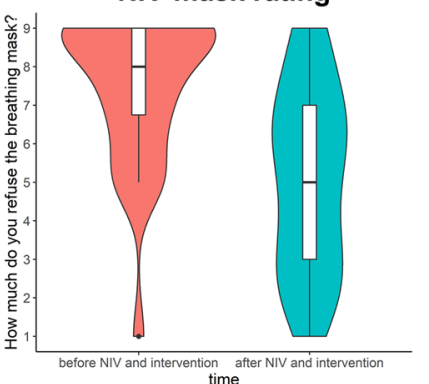

Fig. 1 a Main events of the experiment: 1. Subjective ratings before NIV, 2. NIV, 3. Hypnotic suggestions during NIV while physiological parameters are recorded (3a). b Violin plots of subjective ratings before and after NIV and intervention. Violin plots contain boxplots around the median and colored areas indicating the probability density of the rating scores

medical procedures like non-invasive ventilation that are also applied in patients with coronavirus disease 2019 (COVID-19).

\section{Supplementary Information}

The online version contains supplementary material available at https://doi. org/10.1007/s00134-021-06364-8.

\section{Author details}

${ }^{1}$ Friedrich Schiller University, Institute of Psychology, Jena, Germany. ${ }^{2}$ Department of Anesthesiology and Intensive Care Medicine, Jena University Hospital, Jena, Germany. ${ }^{3}$ Jena University Hospital, Institute of Psychosocial Medicine, Psychotherapy and Psychooncology, Jena, Germany.

\section{Compliance with ethical standards}

\section{Conflicts of interest}

The authors report no conflict of interest.

\section{Open Access}

This article is licensed under a Creative Commons Attribution-NonCommercial 4.0 International License, which permits any non-commercial use, sharing, adaptation, distribution and reproduction in any medium or format, as long as you give appropriate credit to the original author(s) and the source, provide a link to the Creative Commons licence, and indicate if changes were made. The images or other third party material in this article are included in the article's Creative Commons licence, unless indicated otherwise in a credit line to the material. If material is not included in the article's Creative Commons licence and your intended use is not permitted by statutory regulation or exceeds the permitted use, you will need to obtain permission directly from the copyright holder. To view a copy of this licence, visit http://creativecommons.org/licen ses/by-nc/4.0/.

\section{Publisher's Note}

Springer Nature remains neutral with regard to jurisdictional claims in published maps and institutional affiliations.

Received: 20 December 2020 Accepted: 28 January 2021

Published online: 16 February 2021

\section{References}

1. Karnatovskaia LV, Philbrick KL, Parker AM, Needham DM (2016) Early psychological therapy in critical illness. Semin Respir Crit Care Med 37:136-142

2. Nava S, Hill N (2009) Non-invasive ventilation in acute respiratory failure. Lancet 374:250-259

3. Schmidt B, Holroyd CB (2021) Hypnotic suggestions of safety reduce neuronal signals of delay discounting. Sci Rep. https://doi.org/10.1038/ s41598-021-81572-2

4. Schmidt B, Deffner T, Rosendahl I (2020) Feeling safe during intensive care: protocol of a pilot study on therapeutic suggestions of safety under hypnosis in patients with non-invasive ventilation. OBM Integr Complem Med 5(2):8

5. Schmidt B, Hoffmann E, Rasch B (2020) Feel safe and money is less important hypnotic suggestions of safety decrease brain responses to monetary rewards in a risk game. Cerebral Cortex Commun. https://doi. org/10.1093/texcom/tgaa050 